\title{
Lack of CBI Cannabinoid Receptor Impairs Cocaine Self-Administration
}

\author{
Guadalupe Soria', Victoria Mendizábal', Clara Touriño', Patricia Robledo ${ }^{1,2}$, Catherine Ledent ${ }^{3}$, \\ Marc Parmentier ${ }^{3}$, Rafael Maldonado' and Olga Valverde*, \\ 'Laboratori de Neurofarmacologia, Departament de Ciències Experimentals i de la Salut, Universitat Pompeu Fabra, Barcelona, Spain; ${ }^{2}$ IMIM, \\ Institut Municipal d'Investigacions Mèdiques, Barcelona, Spain; ${ }^{3}$ IRIBHM, Université Libre de Bruxelles, Bruxelles, Belgium
}

\begin{abstract}
Acute rewarding properties are essential for the establishment of cocaine addiction, and multiple neurochemical processes participate in this complex behavior. In the present study, we used the self-administration paradigm to evaluate the role of CBI cannabinoid receptors in several aspects of cocaine reward, including acquisition, maintenance, and motivation to seek the drug. For this purpose, both CBI receptor knockout mice and wild-type littermates were trained to intravenously self-administer cocaine under different schedules. Several cocaine training doses (0.32, I, and $3.2 \mathrm{mg} / \mathrm{kg} /$ infusion) were used in the acquisition studies. Only $25 \%$ of CBI knockout mice vs $75 \%$ of their wild-type littermates acquired a reliable operant responding to self-administer the most effective dose of cocaine (I mg/kg/ infusion), and the number of sessions required to attain this behavior was increased in knockout mice. Animals reaching the acquisition criteria were evaluated for the motivational strength of cocaine as a reinforcer under a progressive ratio schedule. The maximal effort to obtain a cocaine infusion was significantly reduced after the genetic ablation of CBI receptors. A similar result was obtained after the pharmacological blockade of CBI receptors with SRI4I7I6A in wild-type mice. Moreover, the cocaine dose-response curve was flattened in the knockout group, suggesting that the differences observed between genotypes were related to changes in the reinforcing efficacy of the training dose of cocaine. Self-administration for water and food was not altered in CBI knockout mice in any of the reinforcement schedules used, which emphasizes the selective impairment of drug reinforcement in these knockout mice. Finally, cocaine effects on mesolimbic dopaminergic transmission were evaluated by in vivo microdialysis in these mice. Acute cocaine administration induced a similar enhancement in the extracellular levels of dopamine in the nucleus accumbens of both CBI knockout and wild-type mice. This work clearly demonstrates that CBI receptors play an important role in the consolidation of cocaine reinforcement, although are not required for its acute effects on mesolimbic dopaminergic transmission.

Neuropsychopharmacology (2005) 30, I670- 1680. doi: I 0. I 038/sj.npp. I 300707; published online 2 March 2005
\end{abstract}

Keywords: CBI cannabinoid receptor; self-administration; cocaine; knockout; in vivo microdialysis; dopamine

\section{INTRODUCTION}

Adaptive changes occurring in different brain areas within the mesocorticolimbic system during repeated drug exposure have been reported to play a crucial role in the consolidation of an addictive behavior (Koob and LeMoal, 2001; Nestler, 2004). Among these structures, the nucleus accumbens (NAc) and its dopaminergic input are considered a common feature mediating the primary reinforcing effects of most drugs of abuse (Di Chiara, 1998). CB1 cannabinoid receptors are important modulators of dopa-

*Correspondence: Dr O Valverde, Laboratori de Neurofarmacologia, Universitat Pompeu Fabra, Dr Aiguader 80, Barcelona 08003, Spain, Tel: + 349354228 31, Fax: + 349354228 02,

E-mail: ovalverde@imim.es

Received 12 November 2004; revised 12 January 2005; accepted 14 January 2005

Online publication: 28 January 2005 at http://www.acnp.org/citations/ NPPO I 2805040534/default.pdf minergic activity in the mesocorticolimbic system, suggesting that the endogenous cannabinoid system may contribute to the addictive properties of different drugs of abuse such as opioids, ethanol, and nicotine. Thus, the pharmacological blockade of CB1 receptors with SR141716A attenuates morphine, heroin, and nicotine self-administration (Cohen et al, 2002; Caillé and Parsons, 2003; Solinas et al, 2003) and inhibits ethanol intake in rodents (Arnone et al, 1997; Freedland et al, 2001). Knockout mice lacking CB1 cannabinoid receptor were generated and characterized (Ledent et al, 1999; Zimmer et al, 1999). The prototypical effects of CB1 cannabinoid agonists such as antinociception, reinforcement, hypothermia, and hypolocomotion were absent in these mice. Moreover, the rewarding properties of nicotine and morphine measured in the conditioned place preference (CPP) and the self-administration paradigm are absent in mice lacking CB1 receptors (Ledent et al, 1999; Martin et al, 2000; Cossu et al, 2001; Castañé et al, 2002). The deletion of CB1 receptors not only abolishes 
WIN 55,212-2 self-administration (Ledent et al, 1999) but also attenuates oral ethanol self-administration and acute alcohol- and morphine-induced dopamine (DA) release in the NAc (Hungund et al, 2003; Mascia et al, 1999). However, several studies suggest that CB1 cannabinoid receptors do not participate in the acute rewarding properties of psychostimulants. Both acute cocaine self-administration performed during a single 30-min session and cocaineinduced CPP were preserved in mice lacking CB1 receptors (Martin et al, 2000; Cossu et al, 2001). On the other hand, CB1 cannabinoid receptor stimulation by WIN 55,212-2 has been reported to decrease the rewarding effects of cocaine in the brain self-stimulation paradigm in mice (Vlachou et al, 2003), whereas the blockade of CB1 receptors by SR141716A decreased the reinforcing value of intracranial self-stimulation in rats (Deroche-Gamonet et al, 2001), suggesting that the endogenous cannabinoid system could modulate motivational states involved in reward processes.

Although acute reinforcing properties are essential for the establishment of drug addiction, other complex behavioral processes are crucial for the consolidation of this chronic relapsing disorder (Koob and LeMoal, 2001). Intravenous drug self-administration is probably the most complete and reliable approach to investigate in animals the abuse potential of drugs in humans. Different aspects of drug addiction can be studied using this paradigm, including acquisition and maintenance of an operant response to obtain a drug, extinction, reinstatement, and relapse. In this sense, an important role of the endocannabinoid system in the neuronal processes underlying cocaine-seeking behavior has been recently demonstrated. Thus, SR141716A attenuates cocaine relapse induced by re-exposure to cocaineassociated cues or cocaine itself (De Vries et al, 2001).

In view of these data, we used the operant selfadministration procedure to evaluate the role of $\mathrm{CB} 1$ receptors in different responses related to cocaine reinforcing effects including acquisition and maintenance of selfadministration behavior, and motivation to seek the drug. For this purpose, both CB1 receptor knockout mice and their wild-type littermates were trained to self-administer different doses of cocaine $(0.32,1$, and $3.2 \mathrm{mg} / \mathrm{kg} /$ infusion) using two schedules of reinforcement, namely fixed ratio 1 (FR1) and progressive ratio (PR). These results were compared to the acquisition of an operant behavior to obtain two natural rewarding stimuli, food and water. We also used wild-type mice to examine the effect of the CB1 receptor antagonist, SR141716A, on cocaine self-administration under a PR schedule of reinforcement. In addition, in vivo microdialysis studies were performed to assess if the acute effects of cocaine on the extracellular levels of DA in the NAc were modified in these knockout animals.

\section{MATERIALS AND METHODS}

\section{Animals}

Male CB1 knockout mice and their wild-type littermates were used in all the experiments. The generation of mice lacking CB1 cannabinoid receptor was described previously by Ledent et al (1999). In order to homogenize the genetic background of the mice, the first-generation heterozygotes were bred for 15 generations on a CD1 background (Charles
River, France) with selection for the mutant $\mathrm{CB} 1$ gene at each generation. The $\mathrm{CB} 1$ receptor knockout mice derived from the backcrossing of chimeric CD1-CB1 receptor knockout mice developed by Ledent et al (1999) with wild-type CD1 females (Charles River, France). Beginning with the 15th generation of backcrossed mice, heterozygote-heterozygote matings of CB1 knockout mice produced wild-type and knockout littermates for subsequent experiments. Breeding couples were periodically renovated by crossing heterozygote mice with wild-type CD1 females (Charles River, France) in order to maintain a genetically diverse outbred background. All mice used in the experiment were originated from the same breeding and were matched for age and weight. Male wild-type CD1 mice used in the SR141716A experiment were purchased from Charles River (France).

Mice weighed 25-30 $\mathrm{g}$ at the beginning of the experiment, and were housed individually in a temperature- $\left(21 \pm 1^{\circ} \mathrm{C}\right)$ and humidity- $(55 \pm 10 \%)$ controlled room. For self-administration studies, mice were exposed to a $12 \mathrm{~h}$ light:dark reversed cycle (light on between 2000 and 0800), and the experiments took place during the dark phase. For microdialysis studies, the light:dark cycle was light on between 0800 and 2000, and the experiments took place during the light phase. Food and water were available ad libitum during the cocaine self-administration and microdialysis experiments, except during the exposure to the self-administration sessions. All animal care and experimental procedures were conducted according to the guidelines of the European Communities Directive 86/609/ EEC regulating animal research and were approved by the local ethical committee (CEEA-IMAS-UPF).

\section{Drugs}

Cocaine hydrochloride was obtained from Ministerio Sanidad y Consumo (Spain) and dissolved in sterile $0.9 \%$ physiological saline. Ketamine hydrochloride $(100 \mathrm{mg} / \mathrm{kg})$ (Imalgène $1000^{\circledR}$, Rhône Mérieux, Lyon, France) and xylazine hydrochloride $(20 \mathrm{mg} / \mathrm{kg}$ ) (Sigma Chemical Co., Madrid, Spain) were mixed and dissolved in absolute ethanol and distilled water $(1: 9)$. The anesthetic mixture was administered in an injection volume of $20 \mathrm{ml} / \mathrm{kg}$ body weight (i.p.). The selective CB1 receptor antagonist SR141716A (generously provided by Sanofi Recherche, Montpellier, France) was dissolved in a solution of $10 \%$ ethanol, $10 \%$ cremophor EL, and $80 \%$ distilled water, and administered i.p. in a volume of $10 \mathrm{ml} \mathrm{kg}$. All the other substances employed were obtained from Sigma Chemical Co, Madrid, Spain.

\section{Operant Self-Administration}

Apparatus. The self-administration experiments were conducted in mouse operant chambers (Model ENV-307A-CT, Medical Associates, Georgia, VT, USA) equipped with two holes, one was selected as active hole for delivering the reinforcer and the other as inactive hole. Nose-poking on the active hole resulted in a reinforcer (food pellet, water, or cocaine infusion), while nose-poking on the inactive hole had no consequences. The chambers were housed in soundand light-attenuated boxes equipped with fans to provide 
ventilation and ambient noise. A removable food and liquid dispenser equidistant between the two nose-pokes permitted delivery of food pellets or water when required. A stimulus light, located above the active hole, was paired contingently with the delivery of the reinforcer. The same operant chambers were used for drug self-administration, except that drinking and food dippers were removed.

Food-maintained behavior. Mice were deprived of food ( $3.5 \mathrm{~g}$ of food was provided daily) during 4 days, in order to obtain $95 \%$ of their initial weight. The same food deprivation regime was maintained during the whole evaluation of food-maintained operant behavior. Water was available ad libitum during this experimental phase. At 4 days after starting food deprivation, mice were trained in the operant chambers to nose-poke for food pellets (Noyes Precision Pellets, Research Diets Inc., USA). Self-administration sessions ( $1 \mathrm{~h}$ daily) were conducted 6 days per week. The house light was on at the beginning of the session for $3 \mathrm{~s}$ and off during all the session. First, mice were trained under an FR1 schedule of reinforcement. A $10 \mathrm{~s}$ time-out period was established after each reinforcement. During this $10 \mathrm{~s}$ period, the cue light was off and no reward was provided on the active hole. Responses on the inactive hole and all the responses during the $10 \mathrm{~s}$ time-out period were also recorded. The session was terminated after 100 reinforcers were delivered or after $1 \mathrm{~h}$, whichever occurred first. The criteria for the acquisition were achieved when mice maintained a stable responding with less than $20 \%$ deviation from the mean of the total number of reinforcers earned in three consecutive sessions ( $80 \%$ of stability), with at least $75 \%$ responding on the active hole, and a minimum of 10 reinforcers per session. Once the acquisition criteria were achieved, the reinforcement schedule was changed to FR3 (data not shown). The same criteria as above were used to move mice from FR3 to PR in which the response requirement to earn an injection escalated according to the following series: 1-2-3-5-12-18-27-40-60-90-135-200-300450-675-1000. The PR session lasted for $2 \mathrm{~h}$ or until mice did not complete the ratio for delivery of one reinforcer within $1 \mathrm{~h}$, and was performed only once. The breaking point to extinguish self-administration behavior was determined in each animal. After each session, mice were returned to their home-cages.

Water-maintained behavior. Mice were first deprived of water ( $20 \mathrm{~min}$ of free water was provided daily) during 2 days and this same water deprivation regime was maintained during the whole evaluation of water-maintained operant behavior. Food was available ad libitum during this experimental phase. At 2 days after starting water deprivation, mice were trained in the operant chambers to nosepoke for water. Water self-administration sessions were conducted as described above for food-maintained responding, except that the food dispenser was changed for a liquid dipper and responses were maintained by water delivered in $10 \mu \mathrm{l}$ over $10 \mathrm{~s}$. First, mice were trained under an FR1 schedule of reinforcement. A $20 \mathrm{~s}$ time-out period was established after each reinforcement. The session was terminated after 100 reinforcers were delivered or after $1 \mathrm{~h}$, whichever occurred first. When mice achieved the acquisi- tion criteria (see Food-maintained behavior), the reinforcement schedule was changed to FR3 (data not shown). The same criteria as above were used to move mice from FR3 to $\mathrm{PR}$, as described above.

Surgery for drug self-administration study. Mice were anesthetized under isoflurane anesthesia (1.5-2.0\%) and then, implanted with indwelling i.v. Silastic catheters as previously described (Caine et al, 1999) with minor modifications. Briefly, a $6 \mathrm{~cm}$ length of silastic tubing $\left(0.3 \mathrm{~mm}\right.$ inner diameter, $0.6 \mathrm{~mm}$ outer diameter) (Silastic ${ }^{\mathbb{R}}$, Dow Corning, Houdeng-Goegnies, Belgium) was fitted to a 22-gauge steel cannula (Semat, Herts, England) that was bent at a right angle and then embedded in a cement disk (Dentalon Plus, Heraeus Kulzer, Germany) with an underlying nylon mesh. The catheter tubing was inserted $1.3 \mathrm{~cm}$ into the right jugular vein and anchored with suture. The remaining tubing ran subcutaneously to the cannula, which exited at the midscapular region. All incisions were sutured and coated with antibiotic ointment (Bactroban, GlaxoSmithKline, Spain). After surgery, animals were allowed to recover for 3 days prior to initiation of self-administration sessions. The catheter was flushed daily with a saline solution containing heparin $(30 \mathrm{UI} / \mathrm{ml})$ in order to maintain its patency. The patency of intravenous catheters was evaluated periodically (approximately every 6 days) and whenever drug self-administration behavior appeared to deviate dramatically from that observed previously, by the infusion of $0.1 \mathrm{ml}$ of tiobarbital $(5 \mathrm{mg} / \mathrm{ml})$ through the catheter. If prominent signs of anesthesia were not apparent within $3 \mathrm{~s}$ of the infusion, the catheter was surgically removed, and a new catheter was implanted in the opposite jugular vein using the surgical procedure described above.

Drug self-administration procedure. Cocaine self-administration sessions were conducted 3 days after surgery using the schedule described above for food and water selfadministration with the following exceptions. Responding was maintained by cocaine $(0.32,1$, and $3.2 \mathrm{mg} / \mathrm{kg} /$ injection) delivered in $23.5 \mu$ l over $2 \mathrm{~s}$. Cocaine was infused via a syringe that was mounted on a microinfusion pump (PHM-100A, Med-Associates, Georgia, VT, USA) and connected via Tygon tubing $(0.96 \mathrm{~mm}$ outer diameter, Portex Fine Bore Polythene Tubing, Portex Limited, Kent, England) to a single-channel liquid swivel (375/25, Instech Laboratories, Plymouth Meeting, PA, USA) and to the mouse intravenous catheters. The swivel was mounted on a counterbalanced arm above the operant chamber. Mice were trained to nose-poke in order to receive a cocaine injection under an FR1 schedule of reinforcement. Selfadministration sessions ( $1 \mathrm{~h}$ daily) started with a priming injection of the drug. The number of reinforcers was limited to 50 infusions per session and each reinforcer was followed by a $30 \mathrm{~s}$ time-out period where active nose-poking had no consequences. The stimulus light signaled delivery of the reinforcer. After mice achieved the acquisition criteria $(80 \%$ of stability in three consecutive sessions, with at least $75 \%$ responding on the active hole, and a minimum of three reinforcers per session), the reinforcement schedule was changed to PR, as described above. For the dose-response curve, new animals were operated and trained to selfadminister cocaine ( $1 \mathrm{mg} / \mathrm{kg}$ /infusion) under an FR1 
schedule of reinforcement under the same conditions as described before. After acquisition (same criteria as above), self-administration of various doses of cocaine $(0.032,0.1$, $0.32,1$, and $3.2 \mathrm{mg} / \mathrm{kg} /$ infusion) was tested during $2 \mathrm{~h}$ using a Latin square design: a single dose was presented each session, and the order of presentation was counterbalanced between mice.

In a second experiment, the effects of the $\mathrm{CB} 1$ receptor antagonist SR141716A on the motivational strength of cocaine as a reinforcer were evaluated in wild-type mice by using a PR schedule. Mice were trained to self-administer cocaine ( $1 \mathrm{mg} / \mathrm{kg} /$ infusion) using the same acquisition criteria as above. After acquisition, animals were pretreated with either vehicle or different doses of SR141716A $(0.3,1$, or $3 \mathrm{mg} / \mathrm{kg}$, i.p.) $30 \mathrm{~min}$ before starting the different $\mathrm{PR}$ sessions, performed as reported in the first experiment. A Latin square design was used to evaluate the effect of the different doses of SR141716A in each animal. PR sessions were performed once daily on subsequent days. The doses of SR141716A were chosen considering the behavioral results previously reported with this antagonist on cocaine self-administration in rats (De Vries et al, 2001).

\section{Microdialysis Procedure}

Surgery and sample recollection. Mice were anesthetized with a ketamine/xylazine mixture $(0.2 \mathrm{ml} / 10 \mathrm{~g}$ body weight, i.p.) and placed in a stereotaxic apparatus with a flat skull (Paxinos and Franklin, 1997). A small hole was drilled on the right side of the skull and the cannula guide (CMA/7, CMA Microdialysis, Stockholm, Sweden) was implanted vertically $1 \mathrm{~mm}$ above the NAc (AP: $+1.5 \mathrm{~mm}$; ML: $-0.9 \mathrm{~mm}$; DV: $-4.0 \mathrm{~mm}$ from the bregma), and then fixed to the skull with dental cement. At 3 days after the surgery, the analytical probe (CMA/7/1mm, CMA Microdialysis, Stockholm, Sweden) was inserted into the guide cannula. At $48 \mathrm{~h}$ after probe implantation, animals were habituated to the experimental environment overnight. The following morning, a ringer solution $(147 \mathrm{mM} \mathrm{NaCl}, 4 \mathrm{mM} \mathrm{KCl}, 2.3$ $\mathrm{CaCl}_{2}$ ) was pumped through the dialysis probe at a constant rate of $1 \mu \mathrm{l} / \mathrm{min}$. Four consecutive 15 -min dialysis samples were then collected for determination of baseline DA levels. Animals then received an i.p. injection of cocaine $(20 \mathrm{mg} / \mathrm{kg})$ and 12 samples were collected every $15 \mathrm{~min}$ and analyzed by HPLC.

Dopamine determination. Dialysate samples $(15 \mu \mathrm{l})$ were injected without any purification into an HPLC apparatus that consisted of a pump linked to an automatic injector (Agilent 1100, Barcelona, Spain), a reverse-phase column (Zorbax SB C18, $3.5 \mu \mathrm{m}, 150 \times 4.6 \mathrm{~mm}$, Agilent Technologies, Barcelona, Spain), and a coulometric detector (Coulochem II, ESA Inc., Chelmsford, USA) with a 5011 analytical cell to quantify DA. The first electrode was fixed at $-100 \mathrm{mV}$ and the second electrode at $+300 \mathrm{mV}$. The composition of the mobile phase was $50 \mathrm{mM} \mathrm{NaH} \mathrm{PO}_{4}$, $0.1 \mathrm{mM} \mathrm{Na}{ }_{2}$ EDTA, $0.65 \mathrm{mM}$ octyl sodium sulfate, and $14 \%$ ( $\mathrm{vol} / \mathrm{vol})$ methanol ( $\mathrm{pH} 3.5)$.

Histology. At the end of the experiments, animals were killed and brains were quickly removed and stored at $-80^{\circ} \mathrm{C}$. In order to check the position of the probe, brains were cut using a cryostat in $20 \mu \mathrm{m}$ serial sections, which were then processed with cresyl violet and observed under a microscope. Only those animals that had been implanted correctly were used in the study.

\section{Statistical Analysis}

Two-way ANOVA, with hole (active or inactive) and genotype (knockout or wild-type) as factors of variation, was calculated on the mean of nose-pokes performed during the last 3 days required to reach the acquisition criteria. This statistical analysis was performed for FR1 in food, water, and cocaine self-administration experiments. Subsequent one-way ANOVA were performed when required. The breaking point values obtained on the PR schedule for food, water, and cocaine self-administration were compared between genotypes by calculating one-way ANOVA. Threeway ANOVA, with hole (active or inactive) and genotype (knockout or wild-type) as between factors, and time as within factor, was used to analyze the acquisition of cocaine self-administration at different training doses. For the cocaine dose-response curve, the number of infusions was compared by repeated measures two-way ANOVA (dose as within-subject factor and genotype as between-subject factor). Subsequent one-way ANOVA were made to calculate differences between genotypes in each dose. One-way ANOVA repeated measures and subsequent Fisher post hoc analysis were performed to determine the effects of SR141716A on breaking point values. Additionally, one-way ANOVA within subjects was performed to discard a day effect in the two experiments using a Latin square design.

The microdialysis data were analyzed using three-way ANOVA with treatment (saline and cocaine) and genotype (wild-type and knockouts) as between-subject factors and time after cocaine injection as within-subject factor. Subsequent two-way ANOVA were performed when required. Unpaired Student's $t$-test was employed to compare DA basal level values between genotypes.

\section{RESULTS}

\section{Food- and Water-Maintained Behavior in Wild-Type and CB1 Knockout Mice}

As shown in Figure 1a, nose-poke behavior maintained by food pellets was acquired by both wild-type and CB1 knockout mice. All the wild-type and CB1 knockout mice reached the FR1 acquisition criteria in $6.5 \pm 0.81$ and $10.33 \pm 1.91$ days, respectively $(\mathrm{F}(1.10)=3.422$; NS). Both genotypes maintained active nose-poke discrimination. Thus, two-way ANOVA showed in FR1 a main effect of nose-poke discrimination $(\mathrm{F}(1.20)=24.157 ; p<0.01)$, and no effect of genotype $(\mathrm{F}(1.20)=0.410$; NS) nor interaction between genotype and nose-poke $(\mathrm{F}(1.20)=0.268$; NS). Subsequent one-way ANOVA showed a significant nosepoke discrimination in wild-type $(\mathrm{F}(1.10)=18.370 ; p<0.01)$ and knockout mice $(\mathrm{F}(1.10)=8.080 ; p<0.01)$. In the case of PR schedule, one-way ANOVA did not reveal differences between the breaking points obtained in wild-type and CB1 knockout groups $(\mathrm{F}(1.10)=0.000$; NS) (Figure $1 \mathrm{~b})$. 

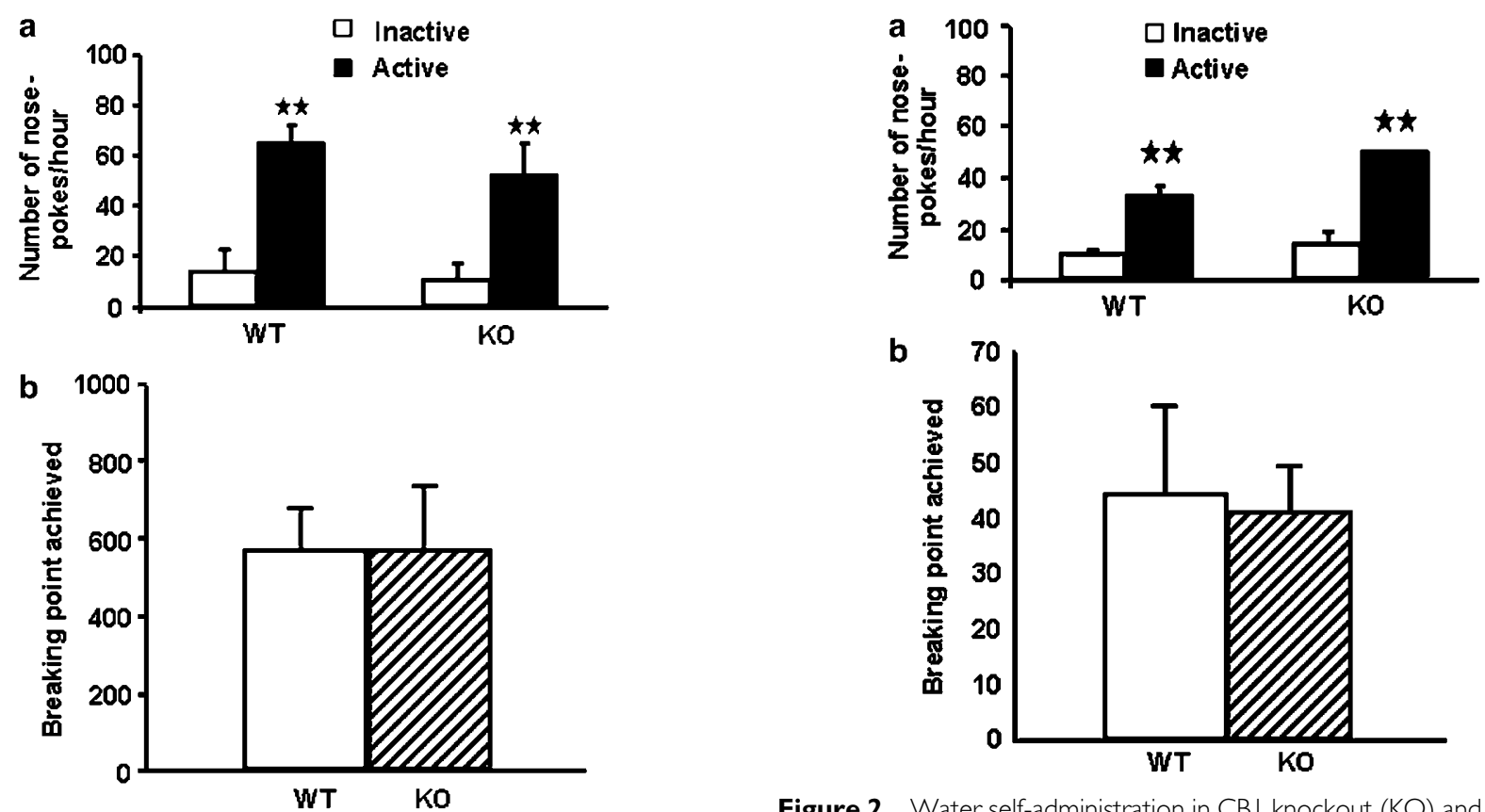

Figure I Food self-administration in $\mathrm{CBI}$ knockout ( $\mathrm{KO}$ ) and wild-type mice (WT). (a) Average of the number of nose-pokes in both the active and the inactive holes made in the three consecutive sessions (I h each) required to achieve the acquisition criteria in FRI schedule of reinforcement. WT mice required $6.5+0.8 \mathrm{I}$ days to achieve these criteria, whereas $\mathrm{KO}$ mice required $10.33 \pm 1.91$ days. (b) Breaking point achieved in PR schedule. Data are expressed as mean \pm SEM ( $n=8$ per group). $\star \star p<0.0$ I comparison between holes (one-way ANOVA).

In order to have further information about operant responding for natural reward, we also tested nose-poke behavior maintained by water delivery in water-deprived mice (Figure 2). All the wild-type and knockout mice achieved the FR1 acquisition criteria in $6.14 \pm 0.99$ and $5.00 \pm 0.71$ days, respectively $(\mathrm{F}(1.10)=0.749 ; \mathrm{NS})$. Both genotypes maintained active nose-poke discrimination. Thus, two-way ANOVA showed in FR1 a main effect of nose-poke discrimination $(\mathrm{F}(1.20)=58.220 ; p<0.01)$, a main effect of genotype $(\mathrm{F}(1.20)=7.022 ; p<0.05)$, but no interaction between genotype and nose-poke $(\mathrm{F}(1.20)=$ 1.401; NS). Subsequent one-way ANOVA showed a significant nose-poke discrimination in wild-type $(\mathrm{F}(1.12)=$ $31.241 ; p<0.01)$ and knockout mice $(\mathrm{F}(1.8)=25.560$; $p<0.01)$. In the PR schedule experiment, no differences were found between the breaking points obtained for the wild-type and knockout groups $(\mathrm{F}(1.10)=0.032$; NS) (Figure 2b).

\section{Cocaine Self-Administration in CB1 Wild-Type and Knockout Mice}

The effects of the $\mathrm{CB} 1$ receptor mutation on the reinforcing properties of cocaine were evaluated by using the operant self-administration procedure. First, both wild-type and knockout mice were trained to self-administer cocaine $(0.32,1$, and $3.2 \mathrm{mg} / \mathrm{kg} /$ infusion) during 10 days under an FR1 schedule of reinforcement (Figure 3). At the dose of $0.32 \mathrm{mg} / \mathrm{kg} /$ infusion, no reliable cocaine self-administration was observed, since the two groups of mice did not discriminate between the active and the inactive holes (see Table 1 for three-way ANOVA) (Figure 3a). The percentage of mice that reached the acquisition criteria was $11 \%$ for wild-type and $13 \%$ for knockout mice. At the dose of $1 \mathrm{mg} /$ $\mathrm{kg} /$ infusion, only the wild-type mice were able to significantly maintain a reliable cocaine self-administration during the whole period (see Table 1 for three-way ANOVA) (Figure $3 \mathrm{~b}$ ). The percentage of mice that reached the acquisition criteria was $75 \%$ for wild-type and $25 \%$ for knockout mice. Subsequent one-way ANOVA revealed that only wild-type mice discriminated between the active and the inactive holes after the second day. At the dose of $3.2 \mathrm{mg} / \mathrm{kg} /$ infusion, mice significantly maintained a reliable cocaine self-administration. However, in the case of knockout mice, cocaine consumption was under a mean of three infusions per hour, this being the reason to fail in achievement of the acquisition criteria (see Table 1 for three-way ANOVA). Subsequent one-way ANOVA revealed that wild-type mice discriminated between the active and the inactive holes after the third day and knockout mice after the eighth day (Figure 3c). The percentage of mice that reached the acquisition criteria was $87.5 \%$ for wild-type mice and $0 \%$ for knockout mice.

The dose of $1 \mathrm{mg} / \mathrm{kg} /$ infusion of cocaine was the most effective to enhance the number of nose-pokes in the active hole in wild-type mice. The highest percentage of knockout mice reaching the acquisition criteria was also obtained with this dose. Therefore, $1 \mathrm{mg} / \mathrm{kg} /$ infusion of cocaine was chosen to train mice for the PR and the dose-response curve experiments. At this dose, wild-type mice achieved 

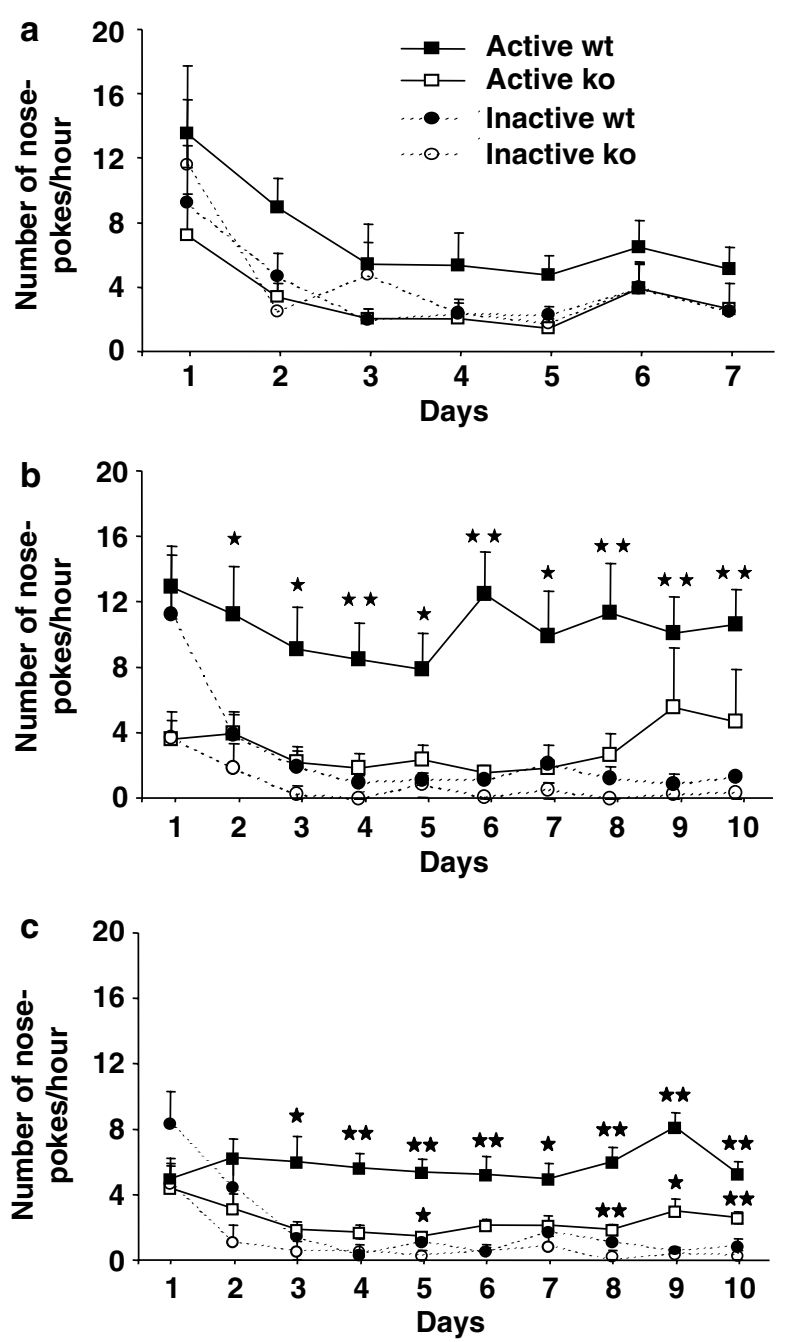

Figure 3 Acquisition of cocaine self-administration in $\mathrm{CB}$ I knockout $(\mathrm{KO})$ and wild-type mice (WT). Number of nose-pokes in both the active hole and the inactive holes in I h session at (a) $0.32 \mathrm{mg} / \mathrm{kg} /$ infusion during 7 days, (b) $1 \mathrm{mg} / \mathrm{kg} /$ infusion during 10 days, and (c) $3.2 \mathrm{mg} / \mathrm{kg} /$ infusion during 10 days. Data are expressed as mean \pm SEM $(n=7-13$ per group). $\star p<0.05 ; \star \star p<0.01$ comparison between either holes (one-way ANOVA). the FR1 stability criteria in $6.11 \pm 0.94$ days, while knockout mice spent $10.22 \pm 1.53$ days for reaching these criteria $(\mathrm{F}(1.17)=6.043 ; p<0.05)$. As shown in Figure $4 \mathrm{a}$, cocaine intake during the 3 days reaching the stability criteria was similar in knockout mice and wild-type littermates. Thus, two-way ANOVA revealed a main effect of nose-poke $(\mathrm{F}(1.320)=37.464 ; \quad p<0.01)$, no effect of genotype $(\mathrm{F}(1.32)=3.135 ; \mathrm{NS})$, nor interaction between these two factors $(\mathrm{F}(1.32)=4.055$; NS). Subsequent one-way ANOVA showed a significant nose-poke discrimination in wildtype $(\mathrm{F}(1.16)=23.899 ; p<0.01)$ and knockout mice
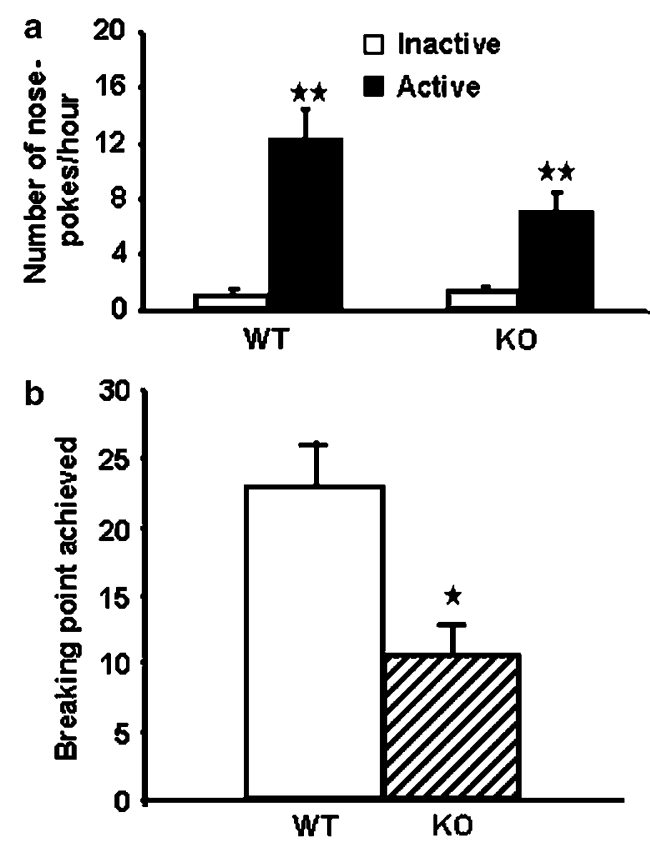

Figure 4 Cocaine self-administration (I mg/ $/ \mathrm{kg} /$ infusion) in CBI knockout (KO) and wild-type mice (WT). (a) Average of the number of nose-pokes in both the active and the inactive holes made in the three consecutive sessions (I h each) required to achieve the acquisition criteria in FRI schedule of reinforcement. (b) Breaking point achieved in PR schedule. Data are expressed as mean \pm SEM ( $n=8-9$ per group). $\star p<0.05$; $\star \star p<0.01$ comparison between either holes or genotypes (one-way ANOVA).

Table I Three-Way ANOVA of Cocaine Self-Administration Time-Course at Different Training Doses

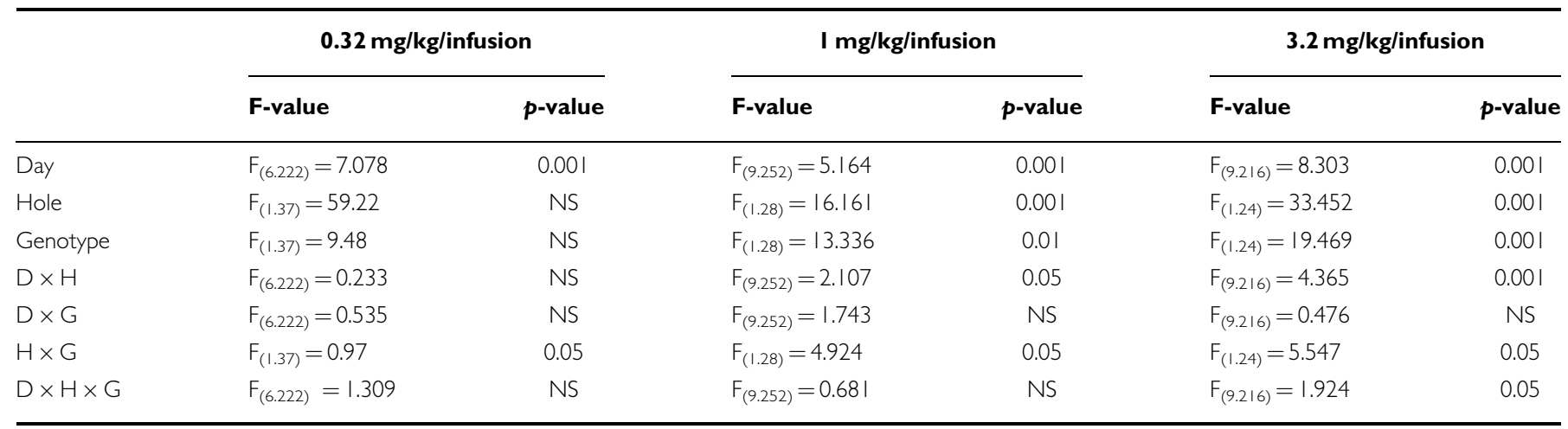

Three-way ANOVA repeated measures with hole $(H)$ and genotype $(G)$ as between-subject factors and day $(D)$ as within-subject factor. See Materials and methods for details. NS: nonsignificant. 


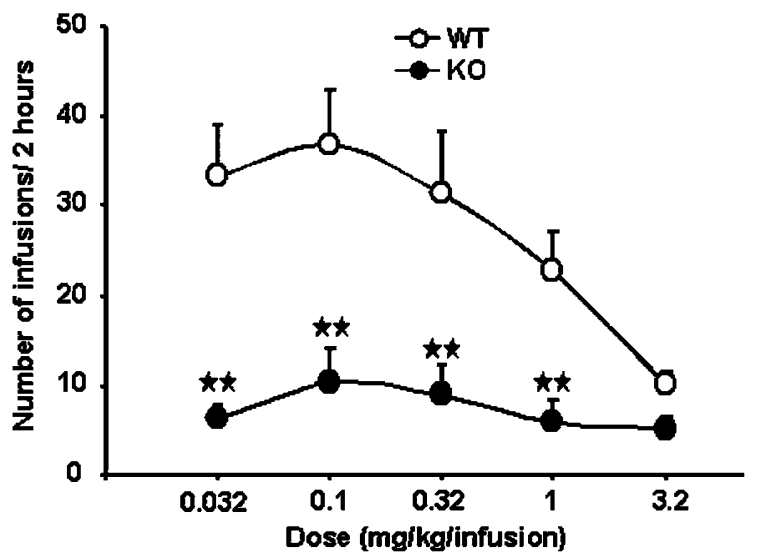

Figure 5 Cocaine dose-response curve in $\mathrm{CBI}$ knockout and wild-type mice. Number of infusions during the 2 -h self-administration session performed at different doses of cocaine are shown. Data are expressed as mean \pm SEM ( $n=8$ per group). $\star \star p<0.01$ comparison between genotypes (one-way ANOVA).

$(\mathrm{F}(1.16)=13.699 ; p<0.01)$. In the case of PR schedule, the breaking point values were significantly reduced in mice lacking the CB1 cannabinoid receptor when compared to wild-type littermates $(\mathrm{F}(1.14)=8.675 ; p<0.05)$ (Figure $4 \mathrm{~b})$.

As shown in Figure 5, a bell-shaped dose-response curve was obtained when different doses of cocaine were tested in wild-type mice, while a flattening of this dose-response curve was observed in the knockout group. Two-way ANOVA with repeated measures revealed a main effect of the treatment $(\mathrm{F}(4.52)=9.139 ; p<0.01)$, genotype $(\mathrm{F}(1.13)$ $=22.405 ; p<0.01)$, and interaction between these two factors $(\mathrm{F}(4.52)=4.938 ; p<0.01)$. One-way ANOVA for treatment revealed a significant dose-response effect in wild-type $(\mathrm{F}(4.34)=4.131 ; p<0.01)$ but not in knockout mice $(\mathrm{F}(4.39)=0.818$; NS). One-way ANOVA for genotype revealed significant differences at the doses of 0.032 $(\mathrm{F}(1.14)=22.932 ; p<0.01), 0.1(\mathrm{~F}(1.14)=15.729 ; p<0.01)$, $0.32(\mathrm{~F}(1.14)=10.123 ; p<0.01), 1(\mathrm{~F}(1.14)=11.994 ; p<0.01)$, and $3.2 \mathrm{mg} / \mathrm{kg} /$ infusion $(\mathrm{F}(1.14)=7.034 ; p<0.05)$. One-way ANOVA revealed no effect of the day in the Latin square design $(\mathrm{F}(4.56)=0.399$; NS).

\section{Effect of SR141716A on Breaking Points Achieved under PR Schedule}

A new group of wild-type mice was trained to selfadminister cocaine under an FR1 schedule of reinforcement using the previously described acquisition criteria. Thus, mice that reached the acquisition criteria $(9.17 \pm 0.65$ days $)$ clearly discriminated between the active and the inactive holes $(\mathrm{F}(1.11)=92.898 ; p<0.01)$, and had $16.56 \pm 1.62$ as average of responses in the 3 days required to achieve these criteria. As shown in Figure 6, the maximal effort to obtain a cocaine infusion under a PR schedule of reinforcement was decreased when mice were previously treated with SR141716A. Thus, one way-ANOVA with repeated measures revealed a dose-dependent effect of SR141716A $(\mathrm{F}(3.15)=$ 5.303; $p<0.01$ ). Subsequent post hoc comparisons showed

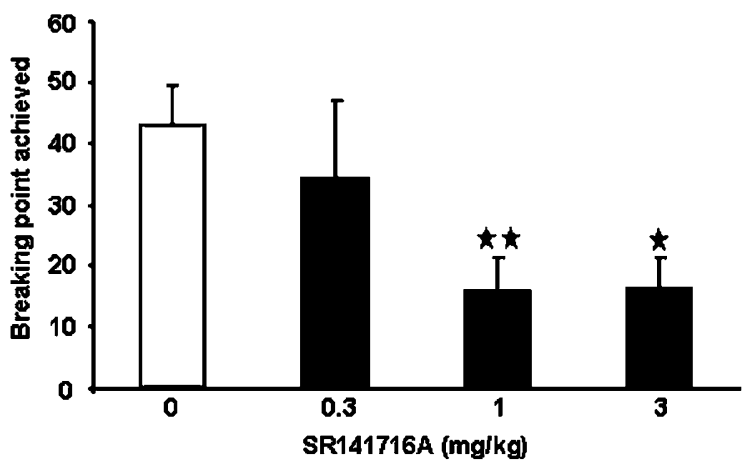

Figure 6 Effects of SRI4I7I6A (0.3, I, and $3 \mathrm{mg} / \mathrm{kg}$, i.p.) on the breaking points achieved under PR schedule. Data are expressed as mean \pm SEM $(n=6) . \star p<0.05 ; \star \star p<0.01$ comparison with vehicle treatment (Fisher post hoc test).
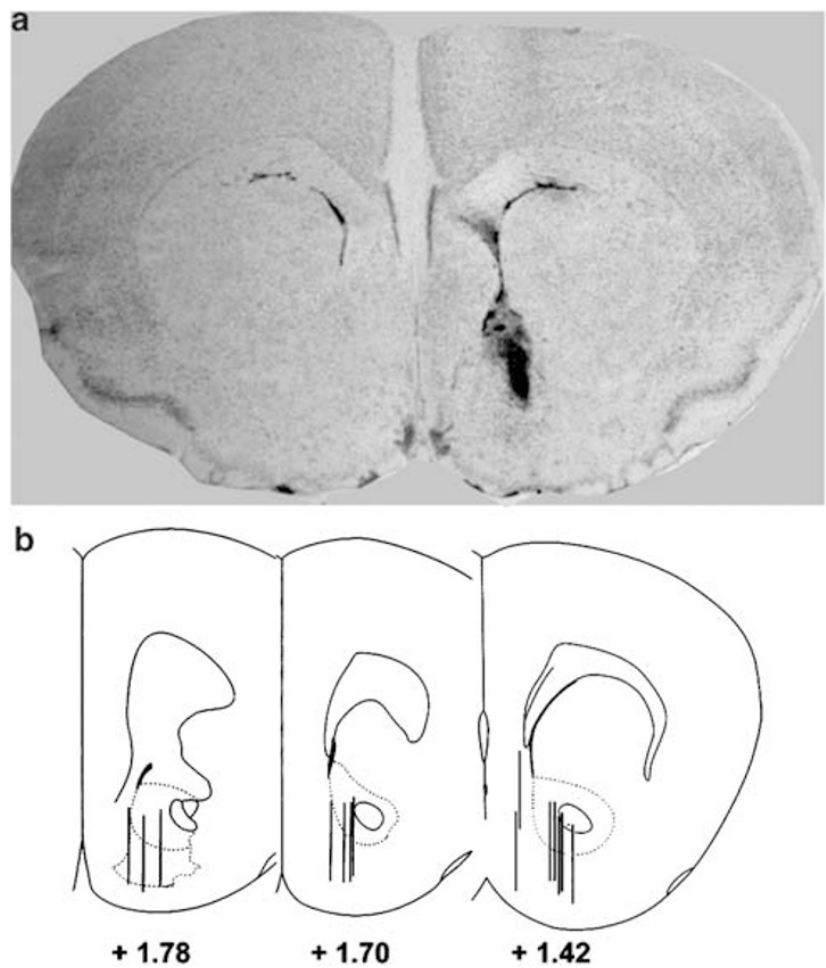

Figure 7 (a) Representative coronal section $(20 \mu \mathrm{m})$ of the mouse brain stained with cresyl violet illustrating the placement of the probe in the nucleus accumbens (bregma $+1.34 \mathrm{~mm}$ ). (b) Diagram showing among bregma +1.78 and $+1.34 \mathrm{~mm}$ the placement of the probes in all the mice included in the experiment.

differences with the doses of $1(p<0.05)$ and $3 \mathrm{mg} / \mathrm{kg}$ $(p<0.05)$ when compared with vehicle.

\section{Dopamine Levels in the Nucleus Accumbens in CB1 Wild-Type and Knockout Mice}

Figure 7 shows a representative coronal section of the mouse brain with the placement of the microdialysis probe through the NAc. Most of the probes were located medial to 


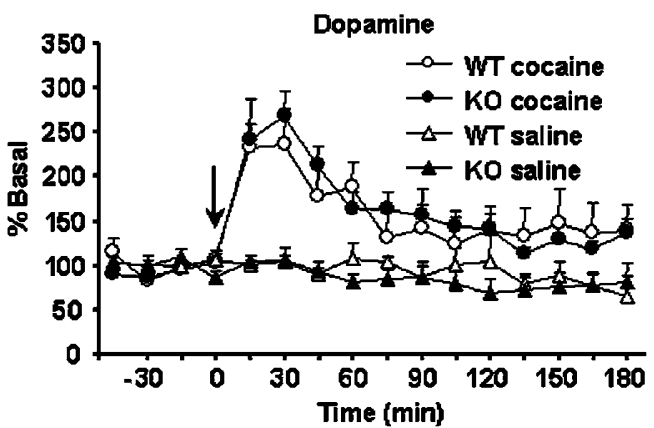

Figure 8 Effects of cocaine $(20 \mathrm{mg} / \mathrm{kg}$, i.p.) and saline on DA concentrations in dialysates obtained by in vivo microdialysis from the NAc of either CBI cannabinoid receptor knockout and wild-type mice. The arrow indicates cocaine or saline administration at time 0 . Dialysate samples were taken every 15 min during I h before, and $3 \mathrm{~h}$ following injection. $\bigcirc$ cocaine-treated wild-type mice; cocaine-treated knockout mice; $\triangle$ saline-treated wild-type mice; $\boldsymbol{\Delta}$ saline-treated knockout mice. All values are expressed as mean \pm SEM ( $n=4-5$ per group).

the anterior commissure, between 1.78 and $1.34 \mathrm{~mm}$ from bregma, and dorsal to the olfactory tubercule.

Basal levels of DA in NAc dialysates were similar in wildtype $(5.63 \pm 0.89 \mathrm{pg} / 15 \mu \mathrm{l})$ and $\mathrm{CB} 1$ cannabinoid receptor knockout mice $(3.93 \pm 0.61 \mathrm{pg} / 15 \mu \mathrm{l}) \quad(t=0.124 ; \mathrm{NS})$. As shown in Figure 8 , cocaine administration $(20 \mathrm{mg} / \mathrm{kg}$, i.p.) increased DA in NAc dialysates of both wild-type and CB1 knockout mice. The maximal increase of DA elicited by cocaine in the NAc of CB1 knockout mice (260\%) did not differ significantly from that of wild-type mice (240\%), and occurred in both groups from 15 to $30 \mathrm{~min}$ after cocaine administration. Three-way ANOVA revealed a significant main effect of time following cocaine injection $(\mathrm{F}(11$, $176)=10.907 ; p<0.01)$ and treatment $(\mathrm{F}(1,16)=238.256$; $p<0.01)$ and no effect of genotype $(\mathrm{F}(1,16)=0.029$; NS). An interaction between time following cocaine injection and treatment was observed $(\mathrm{F}(11,176)=5.226 ; p<0.01)$. No other significant two- or three-way interactions among factors were observed.

\section{DISCUSSION}

This work demonstrates for the first time that CB1 cannabinoid receptors play an important role in the acquisition and maintenance of cocaine self-administration. The present findings suggest a lack of motivation to seek the drug in CB1 knockout mice since (1) only $25 \%$ of CB1 knockout mice acquired a reliable operant responding to self-administer cocaine (1 mg/kg/infusion), (2) the time required for reaching the acquisition criteria was significantly increased in knockout mice, and (3) the maximal effort required to obtain a cocaine infusion was significantly reduced after the genetic ablation of $\mathrm{CB} 1$ receptors. A similar result was obtained after the pharmacological blockade of these receptors with SR141716A in wild-type mice. However, acute cocaine administration induced a similar enhancement of the DA extracellular levels in the NAc in wild-type and CB1 knockout mice.

CB1 receptors have been involved in learning and memory processes (Reibaud et al, 1999; Martin et al,
2002; Varvel and Lichtman, 2002). However, the impairment to self-administer cocaine in these knockout mice does not seem to be the consequence of a learning and memory alteration. Indeed, self-administration for natural rewarding stimuli, such as water and food, was not altered in any of the reinforcement schedules used. This result shows that (1) CB1 knockout mice are able to learn an operant self-administration behavior and (2) CB1 receptors do not control the acquisition and maintenance of an operant responding for natural rewards. These findings are in line with recent studies showing that separate neuronal circuits exist in the NAc that encode information related to cocaine $v s$ natural (food/water) reinforcement (Carelli et al, 2000).

When mice were trained to self-administer different doses of cocaine, a low percentage of CB1 knockout mice (25\%) achieved the acquisition criteria only at the dose of $1 \mathrm{mg} / \mathrm{kg} /$ infusion, whereas wild-type mice efficiently reached the acquisition criteria at the dose of $1(75 \%)$ and $3.2 \mathrm{mg} / \mathrm{kg} /$ infusion (87.5\%). Additionally, knockout mice required a longer training period than their wild-type littermates to reach these criteria. These results are in contrast with a previous study showing that cocaine self-administration was not impaired in CB1 knockout mice under an acute reinforcing paradigm (Cossu et al, 2001). More likely, this apparent disagreement could be due to the different experimental conditions employed. In the previous work, mice with restrained mobility received cocaine $(0.1 \mathrm{mg} / \mathrm{kg} /$ infusion) when a nose-poke response was performed during a single 30 -min session. Our conditions consisted of freely moving animals chronically receiving $1 \mathrm{~h}$ self-administration sessions of cocaine at different training doses $(0.32,1$, and $3.2 \mathrm{mg} / \mathrm{kg} /$ infusion) during several days. Interestingly, those wild-type and knockout mice that achieved the acquisition criteria (wild type: $75 \%$; knockout: $25 \%$ ) showed similar cocaine intake during the first self-administration session (wild type: $8.88 \pm 1.39$; knockout: $6.33 \pm 1.49$ ) and also during the first $30 \mathrm{~min}$ of this session (wild type: $4.63 \pm 0.98$; knockout: $4.00 \pm 0.90$ ). However, the knockout group showed a lower cocaine intake than wild type in the first self-administration session when considering all the animals exposed to this paradigm. The present methodological approach allows to evaluate a complex behavioral response in which the acute reinforcing effects of the drug are only the first step for the acquisition of a stable operant self-administration responding. Under these conditions, our results suggest that $\mathrm{CB} 1$ receptors are largely involved in the acquisition of cocaine self-administration. In agreement, a recent study using the intracranial selfstimulation paradigm showed that $\mathrm{CB} 1$ receptor blockade decreases the rewarding effects of cocaine (DerocheGamonet et al, 2001).

Only the animals that did acquire cocaine self-administration were tested in the PR schedule. Both the breaking points achieved and, consequently, the cocaine intake in this schedule were lower in CB1 knockout mice in comparison with wild-type animals. Accordingly, the cocaine dose-response curve was flattened in the knockout group. The possibility that these differences could be due to changes in sensitivity and/or tolerance to the reinforcing effects of cocaine can be ruled out since knockout mice were unable to self-administer cocaine either at a lower $(0.32 \mathrm{mg} /$ 
$\mathrm{kg} /$ infusion $)$ or higher $(3.2 \mathrm{mg} / \mathrm{kg} /$ infusion $)$ training dose of cocaine. These findings agree with the recent proposal that $\mathrm{CB} 1$ receptors could play a major role in the determination of the hedonic value of sucrose and saccharine, two palatable reinforcers (Sanchís-Segura et al, 2004). In order to discard the possible influence of compensatory changes in CB1 knockout mice in the impairment observed in cocaine self-administration, we evaluated the effects induced by the CB1 receptor antagonist SR141716A on cocaine self-administration in wild-type mice. Mice pretreated with SR141716A (1 and $3 \mathrm{mg} / \mathrm{kg}$ ) showed a clear decrease on the breaking points to obtain cocaine under a PR schedule. This result confirms the findings obtained on CB1 knockout mice and suggests that the behavioral alterations observed in these animals were a direct consequence of $\mathrm{CB} 1$ receptors deletion. Previous studies have demonstrated that SR141716A attenuates relapse induced by re-exposure to cocaine-associated cues or cocaine itself in rats, in spite of the absence of effects of this CB1 antagonist on the acquisition of cocaine selfadministration (De Vries et al, 2001). Hence, the impairment in cocaine self-administration found in these knockout mice could be explained as a lower motivation for maintaining a constant cocaine intake, suggesting a role for $\mathrm{CB} 1$ cannabinoid receptors in the consolidation of an addictive process to this psychostimulant drug.

Increases in DA extracellular levels in the NAc have been related to the primary reinforcing effects of prototypical drugs of abuse, including psychostimulants (Di Chiara, 1998). The present in vivo microdialysis data indicating that cocaine effects in DA extracellular levels in the NAc were not modified in CB1 knockout mice discard the possibility that the decrease of cocaine self-administration in mutants was due to an impaired DA release in the NAc, as reported with other drugs of abuse in CB1 knockout mice (Hungund et al, 2003). In addition, these results are in agreement with our previous behavioral results showing the capability of cocaine to induce $\mathrm{CPP}$ in $\mathrm{CB} 1$ receptor knockout mice (Martin et al, 2000). Moreover, neuroanatomical data reported the absence of $\mathrm{CB} 1$ receptor mRNA and protein in dopaminergic neurons in the ventral tegmental area, suggesting that cannabinoids do not exert a direct control on DA release in the NAc (Herkenham et al, 1991; Matsuda et al, 1993). Instead, postsynaptic interactions between DA D2 receptors and anandamide have been proposed as the basis for endocannabinoid modulation of dopaminergic transmission (Giuffrida et al, 1999). Accordingly, there is increasing evidence supporting that cannabinoids may release DA by disinhibiting dopaminergic cells via inhibition of GABAergic signaling from medium spiny neurons (Van der Stelt and Di Marzo, 2003). Accordingly, the ability of cocaine to increase anandamide and to inhibit, via D2like receptors, GABA transmission was partially prevented following blockade of CB1 cannabinoid receptors (Centonze et al, 2004). Therefore, as observed in the present study, the acute effects of cocaine on DA release, which are mainly produced through inhibition of the DA transporter at the level of the NAc (Giros et al, 1996), would not be expected to change in CB1 cannabinoid receptor knockout mice. The fact that cocaine produced similar increases in DA concentrations in both genotypes is difficult to reconcile with the claim that cocaine functions as a less efficacious reinforcer in the knockout group. However, there are other examples in the literature showing that either genetic or pharmacological approaches can induce profound differences in the self-administration behavior without modifying extracellular levels of DA in the Nac (Chiamulera et al, 2001; Caillé and Parsons, 2003). Moreover, DA-independent neuronal circuits have been also proposed to be involved in the regulation of the reward-related processes (Lupica et al, 2004).

The mesolimbic dopaminergic system, particularly the NAc, has been largely implicated in the reinforcing properties of most drugs of abuse and natural reward (Koob and LeMoal, 2001; Nestler, 2004). Thus, lesions of the NAc impair cocaine self-administration (Zito et al, 1985; Ito et al, 2004), suggesting that this limbic structure plays an essential role in cocaine reinforcement. However, lesions of several brain structures such as the basolateral amygdala, the medial prefrontal cortex, or the hippocampus have also been reported to modify cocaine self-administration (Whitelaw et al, 1996; Weissenborn et al, 1997; Chambers and Self, 2002), indicating the participation of these structures in cocaine-seeking behavior. Since CB1 cannabinoid receptors are highly expressed in basolateral amygdala, medial prefrontal cortex, and hippocampus, a possible explanation for our results could be that the lack of CB1 receptors in these brain structures interfered with cocaineseeking behavior. Cannabinoid system has also been related to neuronal processes underlying reinstatement of cocaineseeking behavior. Thus, the CB1 cannabinoid agonist HU210 provokes relapse to cocaine seeking after prolonged withdrawal periods, and the antagonist SR141716A attenuates this response induced by re-exposure to cocaineassociated cues or cocaine itself (De Vries et al, 2001).

In summary, the present study provides further evidence for the role played by the endocannabinoid system as a common neurobiological substrate underlying drug addictive processes. Indeed, mice lacking CB1 cannabinoid receptor failed to maintain a reliable operant responding for self-administer cocaine although cocaine-induced CPP (Martin et al, 2000) and DA release in the NAc were preserved in these knockout mice. This finding supports the hypothesis that cocaine acute rewarding properties are not enough to develop an addictive behavior and provides evidence for a role of the endocannabinoid system in the acquisition and consolidation of cocaine addiction. The lack of motivation for cocaine observed in CB1 knockout mice could be due not only to the reduction of its reinforcing efficacy, but also to impaired detection, association, and representation of the reward signal or to inadequate responding to the rewarding stimuli. The endocannabinoid system seems to modulate cocaine addiction through neuronal circuits different from its acute effects on DA activity in the NAc, which is a prominent substrate for drug rewarding effects.

\section{ACKNOWLEDGEMENTS}

This study was supported by grants from Spanish MCYT (SAF 2001/0745 and SAF 2004/0568 and GEN2003-20651C06-04), HFSP (RG007/200-B), Generalitat de Catalunya (Distinció de la Generalitat and 2002SGR00193), Redes del 
Instituto de Salud Carlos III (C03/06 and G03/005), and European Communities QLRT 2001-01691. CT is a fellowship from DURSI (Generalitat de Catalunya). PR is a researcher supported by FIS Programme. VM is a fellow supported by Fundación Carolina.

\section{REFERENCES}

Arnone M, Maruani J, Chaperon F, Thiebot MH, Poncelet M, Soubrie $\mathrm{P}$ et al (1997). Selective inhibition of sucrose and ethanol intake by SR 141716, an antagonist of central cannabinoid (CB1) receptors. Psychopharmacology 132: 104-106.

Caille S, Parsons LH (2003). SR141716A reduces the reinforcing properties of heroin but not heroin-induced increases in nucleus accumbens dopamine in rats. Eur J Neurosci 18: 3145-3149.

Caine SB, Negus SS, Mello NK (1999). Method for training operant responding and evaluating cocaine self-administration behavior in mutant mice. Psychopharmacology 147: 22-24.

Carelli RM, Ijames SG, Crumling AJ (2000). Evidence that separate neural circuits in the nucleus accumbens encode cocaine versus 'natural' (water and food) reward. J Neurosci 20: 4255-4266.

Castañé A, Valjent E, Ledent C, Parmentier M, Maldonado R, Valverde O (2002). Lack of CB1 cannabinoid receptors modifies nicotine behavioural responses, but not nicotine abstinence. Neuropharmacology 43: 857-867.

Centonze D, Battista N, Rossi S, Mercuri NB, Finazzi-Agrò A, Bernardi $G$ et al (2004). A critical interaction between dopamine D2 receptors and endocannabinoids mediates the effects of cocaine on striatal GABAergic transmission. Neuropsychopharmacology 29: 1488-1497.

Chambers RA, Self DW (2002). Motivational responses to natural and drug rewards in rats with neonatal ventral hippocampal lesions: an animal model of dual diagnosis schizophrenia. Neuropsychopharmacology 27: 889-905.

Chiamulera C, Epping-Jordan MP, Zocchi A, Marcon C, Cottiny C, Tacconi $S$ et al (2001). Reinforcing and locomotor stimulant effects of cocaine are absent in mGluR 5 null mutant mice. Nat Neurosci 4: 873-874.

Cohen C, Perrault G, Voltz C, Steinberg R, Soubrie P (2002). SR141716, a central cannabinoid (CB1) receptor antagonist, blocks the motivational and dopamine-releasing effects of nicotine in rats. Behav Pharmacol 13: 451-463.

Cossu G, Ledent C, Fattore L, Imperato A, Bohme GA, Parmentier $M$ et al (2001). Cannabinoid CB1 receptor knockout mice fail to self-administer morphine but not other drugs of abuse. Behav Brain Res 118: 61-65.

Deroche-Gamonet V, Le Moal M, Piazza PV, Soubrie P (2001). SR141716, a CB1 receptor antagonist, decreases the sensitivity to the reinforcing effects of electrical brain stimulation in rats. Psychopharmacology 157: 254-259.

De Vries TJ, Shaham Y, Homberg JR, Crombag H, Schuurman K, Dieben J et al (2001). A cannabinoid mechanism in relapse to cocaine seeking. Nat Med 47: 1151-1154.

Di Chiara G (1998). A motivational learning hypothesis of the role of mesolimbic dopamine in compulsive drug use. J Psychopharmacol 12: 54-67.

Freedland CS, Sharpe AL, Samson HH, Porrino LJ (2001). Effects of SR141716A on ethanol and sucrose self-administration. Alcohol Clin Exp Res 25: 277-282.

Giros B, Jaber M, Jones SR, Wightman RM, Caron MG (1996). Hyperlocomotion and indifference to cocaine and amphetamine in mice lacking the dopamine transporter. Nature 379: 606-612.

Giuffrida L, Parsons LH, Kerr TM, Rodriguez de Fonseca F, Navarro M, Piomelli D (1999). Dopamine activation of endogenous cannabinoid signaling in dorsal striatum. Nat Neurosci 2: 358-363.

Herkenham M, Lynn AB, Johnson MR, Melvin LS, de Costa BR, Rice KC (1991). Characterization and localization of cannabinoid receptors in rat brain: a quantitative in vitro autoradiographic study. J Neurosci 11: 563-583.

Hungund BL, Szakall I, Adam A, Basavarajappa BS, Vadasz C (2003). Cannabinoid CB1 receptor knockout mice exhibit markedly reduced voluntary alcohol consumption and lack alcohol-induced dopamine release in the nucleus accumbens. J Neurochem 84: 698-704.

Ito R, Robbins TW, Everitt BJ (2004). Differential control over cocaine-seeking behavior by nucleus accumbens core and shell. Nat Neurosci 7: 389-397.

Koob GF, LeMoal M (2001). Drug addiction, dysregulation of reward, and allostasis. Neuropsychopharmacology 24: 97-129.

Ledent C, Valverde O, Cossu G, Petitet F, Aubert JF, Beslot F et al (1999). Unresponsiveness to cannabinoids and reduced addictive effects of opiates in CB1 receptor knockout mice. Science 283: 401-404.

Lupica CR, Riegel AC, Hoffman AF (2004). Marijuana and cannabinoid regulation of brain reward circuits. Br J Pharmacol 143: 227-234.

Martin M, Ledent C, Parmentier M, Maldonado R, Valverde O (2000). Cocaine, but not morphine, induces conditioned place preference and sensitization to locomotor responses in CB1 knockout mice. Eur J Neurosci 12: 4038-4046.

Martin M, Ledent C, Parmentier M, Maldonado R, Valverde O (2002). Involvement of CB1 cannabinoid receptors in emotional behavior. Psychopharmacology 159: 379-387.

Mascia MS, Obinu MC, Ledent C, Parmentier M, Bohme GA, Imperato A et al (1999). Lack of morphine-induced dopamine release in the nucleus accumbens of cannabinoid $\mathrm{CB}(1)$ receptor knockout mice. Eur J Pharmacol 383: R1-R2.

Matsuda LA, Bonner TI, Lolait SJ (1993). Localization of cannabinoid receptor mRNA in rat brain. J Comp Neurol 327: $535-550$.

Nestler EJ (2004). Historical review: molecular and cellular mechanisms of opiate and cocaine addiction. Trends Pharmacol Sci 25: 210-218.

Paxinos G, Franklin KBJ (1997). The Mouse Brain in Stereotaxic Coordinates. Academic: San Diego. Vol 1, pp 268-272.

Reibaud M, Obinu MC, Ledent C, Parmentier M, Bohme GA, Imperato A (1999). Enhancement of memory in cannabinoid CB1 receptor knock-out mice. Eur J Pharmacol 379: R1-R2.

Sanchís-Segura C, Cline BH, Marsicano G, Lutz B, Spanagel R (2004). Reduced sensitivity to reward in CB1 knockout mice. Psychopharmacology 176: 223-232.

Solinas M, Panlilio LV, Antoniou K, Pappas LA, Goldberg SR (2003). The cannabinoid CB1 antagonist SR-141716A, differentially alters the reinforcing effects of heroin under continuousreinforcement, fixed-ratio and progressive-ratio schedules of drug self-administration in rats. J Pharmacol Exp Ther 306: 93-102.

Van der Stelt M, Di Marzo V (2003). The endocannabinoid system in the basal ganglia and in the mesolimbic reward system: implications for neurological and psychiatric disorders. Eur $J$ Pharmacol 480: 133-150.

Varvel SA, Lichtman AH (2002). Evaluation of CB1 receptor knockout mice in the Morris water maze. J Pharmacol Exp Ther 301: 915-924.

Vlachou S, Nomikos GG, Panagis G (2003). WIN 55,212-2 decreases the reinforcing actions of cocaine through CB1 cannabinoid receptor stimulation. Behav Brain Res 141: 215-222.

Weissenborn R, Robbins TW, Everitt BJ (1997). Effects of medial prefrontal or anterior cingulate cortex lesions on responding for cocaine under fixed-ratio and second-order schedules of reinforcement in rats. Psychopharmacology 134: 242-257. 
Whitelaw RB, Markou A, Robbins TW, Everitt BJ (1996). Excitotoxic lesions of the basolateral amygdala impair the acquisition of cocaine-seeking behaviour under a second-order schedule of reinforcement. Psychopharmacology 127: 213-224.

Zimmer A, Zimmer AM, Hohmann AG, Herkenham M, Bonner TI (1999). Increased mortality, hypoactivity, and hypoalgesia in cannabinoid CB1 receptor knockout mice. Proc Natl Acad Sci USA 96: 5780-5785.

Zito KA, Vickers G, Roberts DC (1985). Disruption of cocaine and heroin self-administration following kainic acid lesions of the nucleus accumbens. Pharmacol Biochem Behav 23: $1029-1036$. 